\title{
Study on the Performance of a Sirocco Fan (Optimum Design of Blade Shape)
}

\author{
Tsutomu Adachi, ${ }^{1}$ Naohiro Sugita, ${ }^{1}$ and Yousuke Yamada ${ }^{2}$ \\ ${ }^{I}$ Department of Mechanical Engineering for Transportation, Osaka Sangyo University, Osaka, Japan; \\ ${ }^{2}$ Toshiba Corporation, Japan
}

\begin{abstract}
A sirocco fan is a centrifugal fan with a forward curved blade. It is used for low pressure but has a large discharge use. In this paper, at first, nine impellers with various blade shapes were tested in the same casing. The measurements of the three-dimensional time variant velocity at the outlet of the impeller were done using four impellers having better performances among them. The relations between fan performance and outlet velocity were considered. The effects of the blade shape on the performance were considered. The blade inlet and outlet angles and blade inclination angles which have the best performance were considered. The design parameters of designing a sirocco fan impeller was described.
\end{abstract}

Keywords Sirocco fan, Centrifugal fan, Design of sirocco fan, Flow measurement, Hot wire probe

\section{INTRODUCTION}

A sirocco fan is a centrifugal fan with a forward curved blade. It is used for low pressure but has a large discharge use. The outlet port of this fan may have a rectangular shape and it is sometimes contained in air conditioning apparatus. Indeed, a forward-curved vane can give large momentum to the fluid, but it cannot make for better efficiency. According to the measured results by Kadota et al. (1986) and Kawaguchi et al. (1994) on the flow in the neighborhood of the outlet of a moving blade, uniform flow cannot be obtained because of a sudden turning of the inlet flow. Yamazaki and Sato (1986) and Nakajima et al. (1986, 1988) found a large vortex on the shroud side. Totsuka et al. (1996) showed that the occurrence of turbulence is sometimes

Received in final form on 26 July 2001.

Address correspondence to Tsutomu Adachi, Department of Mechanical Engineering for Transportation, Faculty of Engineering, Osaka Sangyo University, 3-1-1, Nakagaito, Daito, Osaka, Japan (574-8530). E-mail: adachi@tm.osaka-sandai.ac.jp suppressed because the inlet flow into the forward curved vane of the centrifugal fan is the increasing flow. Morinushi (1991) reports on the noise source arising from the separating flow. Ogino (1998) reports on the optimum condition to design the best performance for the sirocco fan. Yet now there are many unknown parameters to decide the best conditions of blade shapes.

In this study, nine runner blades with various blade shapes were tested in the same casing. The measurements of the threedimensional time variant velocity were done using four runner blades having better performances among them. The relations between fan performance and outlet velocity were considered. The effects of blade shape on the performance were considered with the purpose to alter the design method of the sirocco fan impeller. Then, optimum conditions to design a impeller with the best performance were considered.

\section{THE PERFORMANCE TESTS}

\section{Experimental Methods and Apparatus}

Nine impellers that were used in this study are shown in Table I. These impellers have outer and inner diameters of $D_{1}=$ $130 \mathrm{~mm}$ and $D_{2}=160 \mathrm{~mm}$. There are 36 blades, excepting impeller I. The inclination angle denotes the angle which makes the line connecting the inlet and outlet of the blade with the radial line that goes through the inlet edge of the blade. The forward inclination takes the positive values and the backward inclination takes the negative ones, respectively, as shown in Fig. 1. Figure 2 shows a schematic of the experimental apparatus. To regulate the discharge, the opening of a damper placed at the end of the duct was changed. The pressure difference between the up and down side of the orifice plate, the static pressure on the wall, and the input electrical power were measured. These measurements were done for various rotational speeds, i.e., 800 , 1200, 1600, 2000, 2400, 2800 and 3100 rpm, respectively.

\section{Results of Performance Tests}

Figure 3 shows the test results of variations of total pressure coefficient, and the efficiency with a discharge coefficient for 
TABLE I

Dimensions of impellers

\begin{tabular}{|c|c|c|c|c|c|c|c|c|c|c|c|}
\hline Impeller & $\begin{array}{c}\text { Inlet } \\
\text { diameter } \\
D_{1}(\mathrm{~mm})\end{array}$ & $\begin{array}{c}\text { Outlet } \\
\text { diameter } \\
D_{2}(\mathrm{~mm})\end{array}$ & $\begin{array}{l}\text { Chord } \\
\text { length } \\
1(\mathrm{~mm})\end{array}$ & $\begin{array}{l}\text { Blade } \\
\text { wide } \\
b(\mathrm{~mm})\end{array}$ & $\begin{array}{c}\text { Blade } \\
\text { inclination } \\
\theta \text { (deg.) }\end{array}$ & $\begin{array}{c}\text { Inlet } \\
\text { angle } \\
\beta_{1} \text { (deg.) }\end{array}$ & $\begin{array}{c}\text { Outlet } \\
\text { angle } \\
\beta_{2} \text { (deg.) }\end{array}$ & $\begin{array}{c}\text { Inclination } \\
\text { ratio } \\
\text { |Ir| }\end{array}$ & $\begin{array}{c}\text { Blade } \\
\text { thickness } \\
t(\mathrm{~mm})\end{array}$ & $\begin{array}{l}\text { Blade } \\
\text { channel } \\
Y(\mathrm{~mm})\end{array}$ & $\begin{array}{c}\text { Number } \\
\text { of blade } \\
Z\end{array}$ \\
\hline I & 139.00 & 159.88 & 13.42 & 49.30 & 441 & 103.78 & 154.48 & 0.425 & 1.1 & 11.3 & 38 \\
\hline II & 133.46 & 159.29 & 14.48 & 47.70 & 31.38 & 77.51 & 156.32 & 0.405 & 1.0 & 11.8 & \\
\hline III & 124.03 & 156.12 & 17.24 & 46.30 & -24.49 & 14.35 & 121.93 & 1.707 & & 10.5 & \\
\hline IV & 128.17 & 16 & 16.45 & 46.40 & -13 & 11.59 & 143.88 & 1.178 & 2.0 & 10.6 & \\
\hline V & 133.50 & 163 & 15.86 & 46.00 & 20.29 & 83.76 & 132.95 & 0.242 & & 10.9 & \\
\hline VI & 128.85 & 163.42 & 19.80 & 46.40 & 33.21 & 86 & 152.38 & 0.384 & 2.4 & 10.6 & 36 \\
\hline VII & 129.90 & 161.60 & 17.40 & 46.10 & 27.30 & 92.88 & 136.06 & 0.293 & 2.3 & 10.7 & \\
\hline VIII & 131.00 & 159.98 & 17.07 & 46.40 & 35.67 & 89.38 & 154.80 & 0.398 & 2.4 & 10.3 & \\
\hline IX & 130.13 & 160.10 & 19.63 & 46.20 & 45.54 & 93.09 & 167.91 & 0.489 & 2.1 & 10.6 & \\
\hline
\end{tabular}

nine runner blades. The blade inlet angles for impeller III and IV are chosen to get collision-free inlet flow to the runner at the design discharge. These inlet blade angles have smaller values as shown in Table I. Indeed, the maximum efficiencies for these impellers take comparatively larger values, and, therefore, they cannot get larger discharges. Other runner blades can take larger discharges. For impeller VIII, the blade thickness is larger, but the other dimensions, i.e., the inlet and outlet angles, blade inclination, and so on, are almost the same as those with impeller II. The total pressure coefficient becomes smaller but the maximum efficiency at the large discharge takes nearly the same value as that of the impeller II. From these, the inlet angle is properly decided to be $90^{\circ}$.

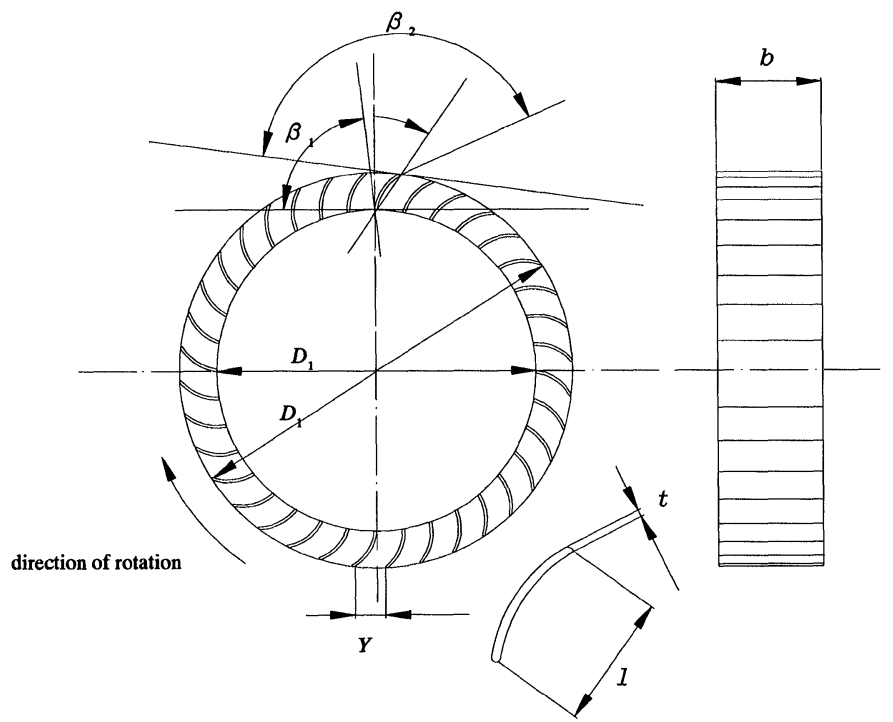

FIGURE 1

Impeller

\section{VELOCITY DISTRIBUTION AT THE OUTLET OF BLADE}

\section{Experimental Method and Apparatus}

A hot wire probe, as shown in Fig. 4, was used to measure velocity distributions at the outlet from the impeller blade. Tungsten wire with $4 \mu$ thickness and $1 \mathrm{~mm}$ length is attached with an angle of $45^{\circ}$. The inserting part of the probe is also shown in the same figure. The hot wire probe can be inserted in four various ways. To measure velocity and its direction, measurements were made four times at the same positions. The probe axis was directed to the angle $\left(\pi-\beta_{2}\right)$. Then the distance of tungsten wire and the outer surface of the impeller was $0.5 \mathrm{~mm}$ as shown in Fig. 5. The number of revolutions was set to $800 \mathrm{rpm}$. It was set to a lower number of revolutions to avoid the damage from vibration. The probe was traversed in the axial direction and measurements were done at five points with equal distance apart from the shroud to the hub as shown in Fig. 6, i.e., a, b, c, d, e. Samplings were started by the signal when the fixed position was at the fixed distance to the probe. The sampling

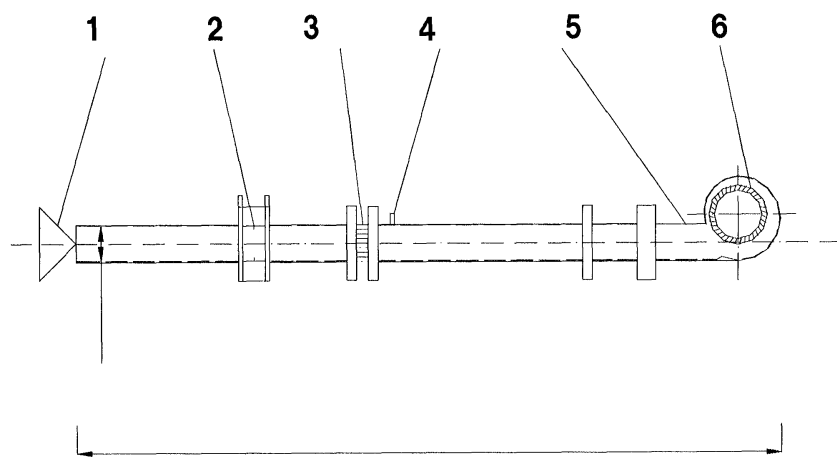

1 damper, 2 orifice, 3 honeycomb

4 static pressure hole, 5 casing, 6 impeller

FIGURE 2

Experimental apparatus. 

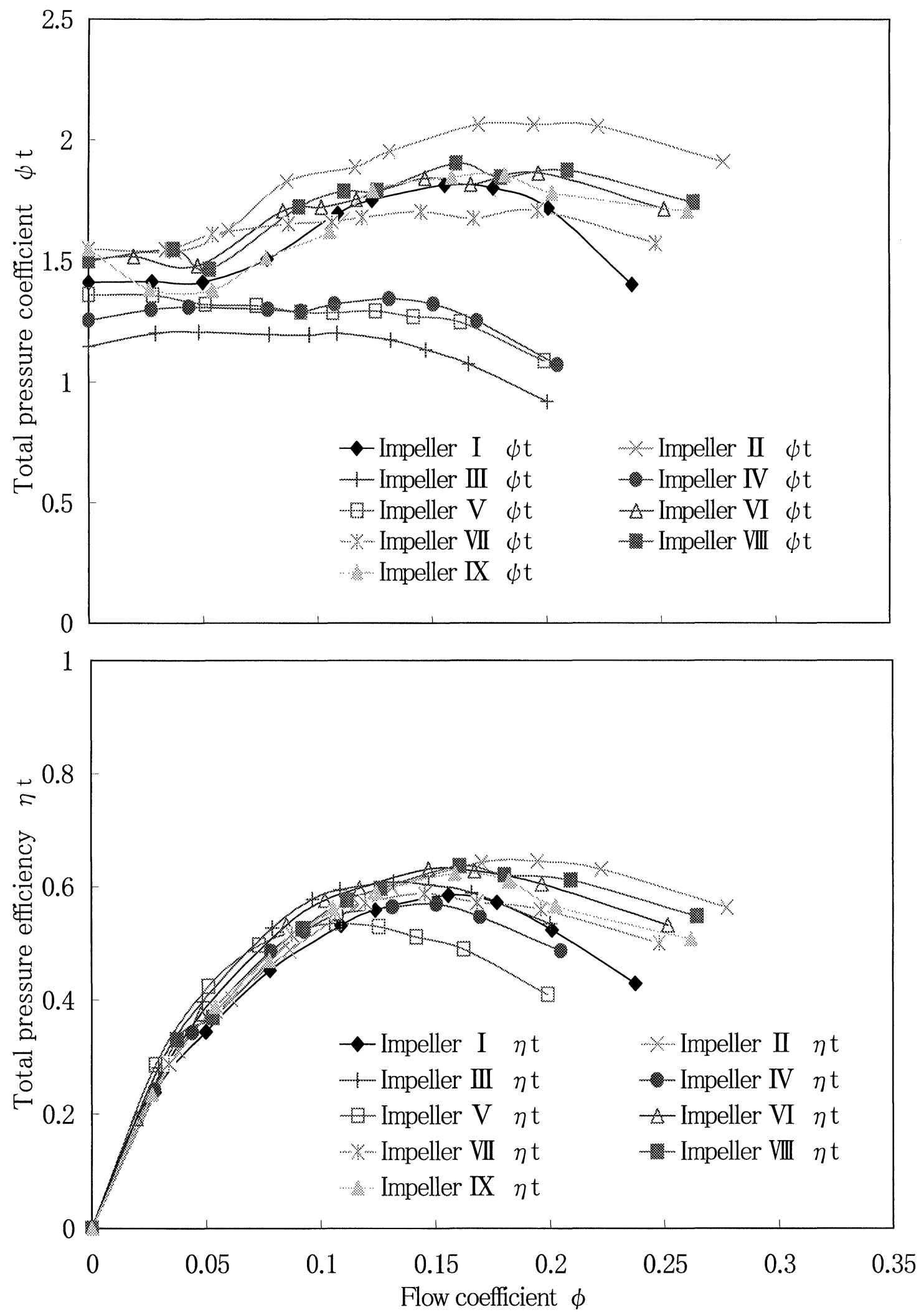

FIGURE 3

Performance curves. 

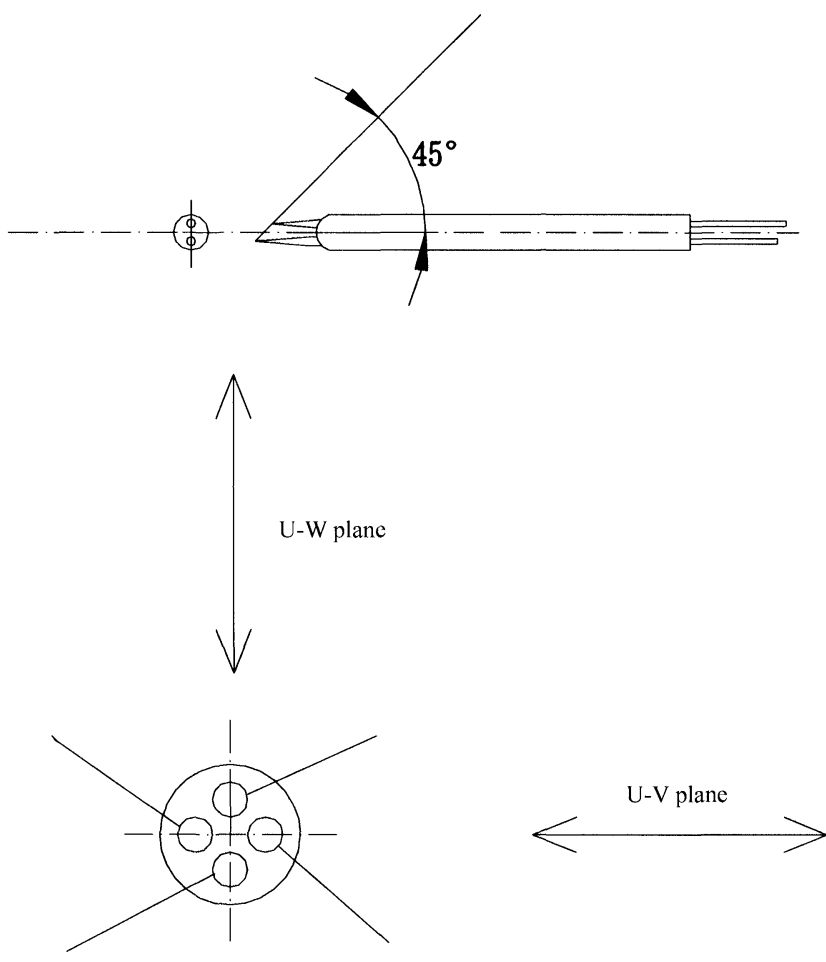

FIGURE 4

Hot wire probe and inserting hole.

time was set to collect data on four points at equal distance of one blade pitch. Every data was summed up $2^{8}$ times and the time-averaged value was measured. Then the random components disappeared from the signal. This method of measurement was reported by Adachi et al. (1995). The magnitude of velocity and its direction was calculated from these four signals taken at four various measuring holes and at the same measuring point. To show the measured results, two planes were taken. One is the $\mathrm{U}-\mathrm{V}$ plane, i.e., the plane including the fan axis, and the other is the U-W plane, i.e., the meridian plane. Observations of the flow were made at the design discharge and at the maximum discharge conditions.

\section{The Flow in the Meridian Plane}

\section{Distributions of Relative Velocity}

Figure 7 shows the velocity triangle at the outlet of the impeller. Distributions of outlet velocity were considered by calculating the parameters, as shown in this figure, from the measured absolute velocities. Relative velocity distributions were shown in Figs. 8 and 9. Impeller I was manufactured by bending a thin aluminum plate. There were bent parts at both ends, as shown in Fig. 10. Then the measuring points for this blade were taken at inner parts avoiding these two bent parts.

According to the results of the visual experiments, the flow through the blade passage of a sirocco fan is said to separate at the leading edge and reattach at the trailing edge of the suction surface. Then the flow at the outlet of the impeller flows along the

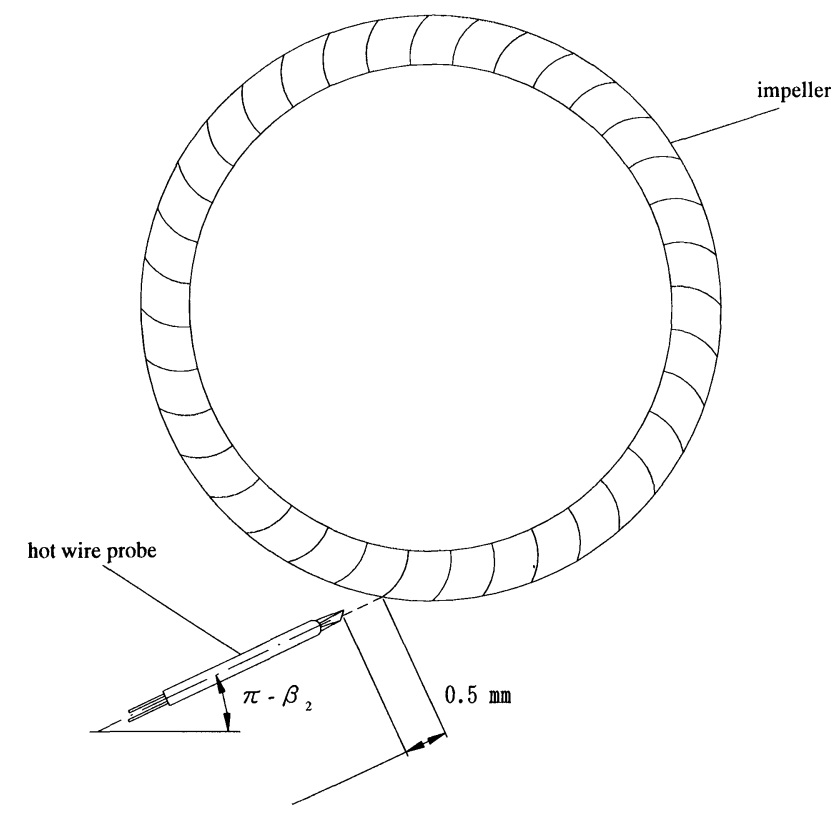

FIGURE 5

Measuring positions.

blade as reported by Yamamoto et al. (1995). The relative outlet velocity $W_{2}$ at points a and e of impeller I is small. The velocity triangle shows the radial velocity component is also small and flow disturbance can also be seen. It may be considered that this disturbance comes from the bent part at both ends, as is written by Kawaguchi et al. (1994).

The flow velocity at the center for the blade is larger on the pressure surface and smaller on the suction surface for impellers II and VIII. Raj and Swim (1981) reports that the flow velocity through a sirocco fan to be larger on the pressure surface, i.e., the jet region, and smaller on the suction surface, i.e., the wake region. For impeller IX the blade inclination and blade outlet angle are large. The blade turning angle is large for this blade. It may be considered that the secondary flow in the blade passage arises and a local wake may arise on the trailing edge of the pressure side of the blade. The cause of the retarding flow may come from this large rotation.

\section{Deviation Angle}

The deviation angle which is defined by

$$
\delta=\beta_{2}-\gamma_{2}
$$

shows large values at every points and especially at a and e points for impeller I. It is considered that it comes from the bent parts at both sides of the impeller. Effects of large separation at both ends influences the central parts. The deviation angle and separation becomes smaller with the decrease in the discharge.

The deviation angle is nearly zero for runner II, irrespective of discharge. The outlet flow goes along the blade. The deviation angle is small, then the outlet flow goes along the blade at the 


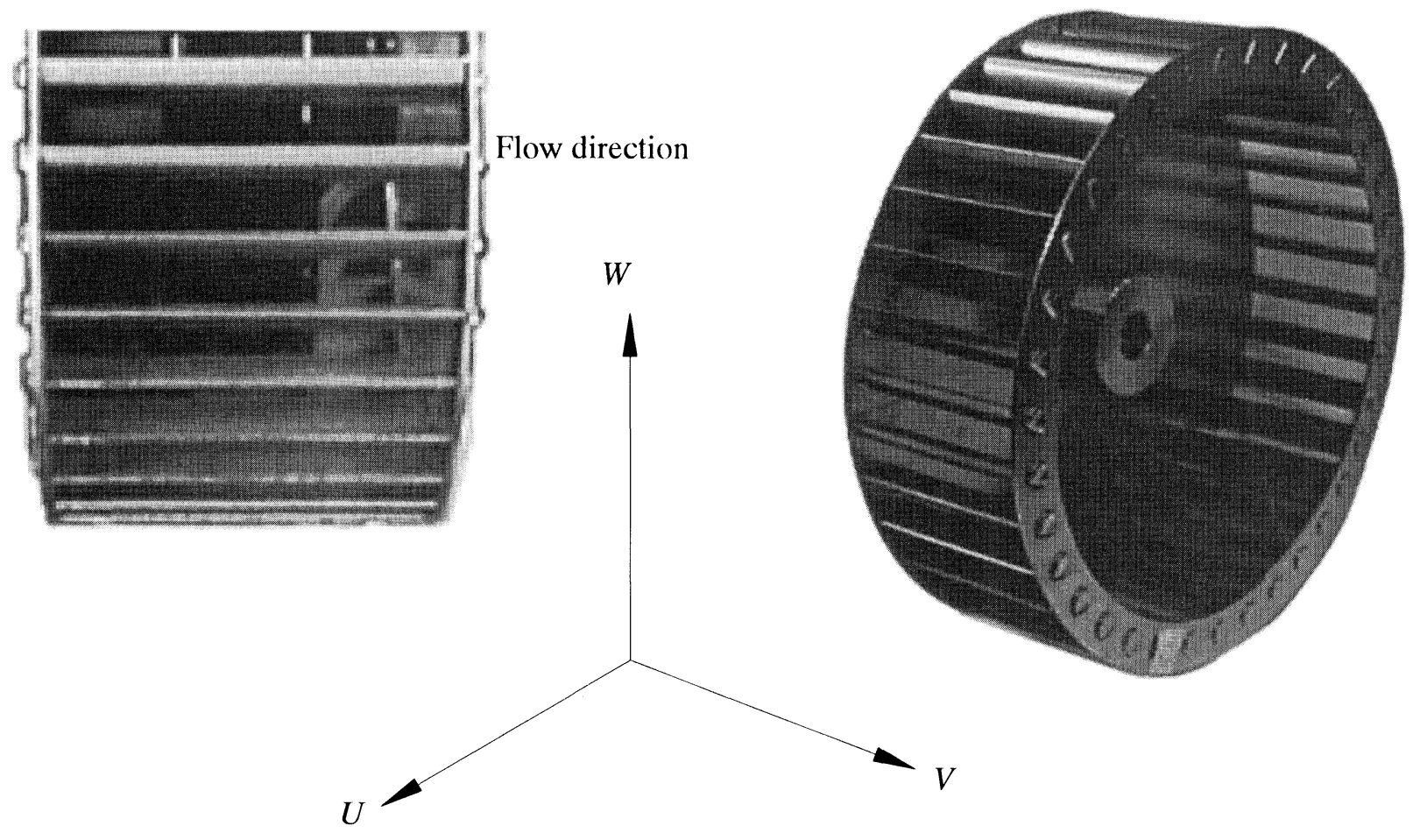

FIGURE 6

Measuring positions and coordinate axis.

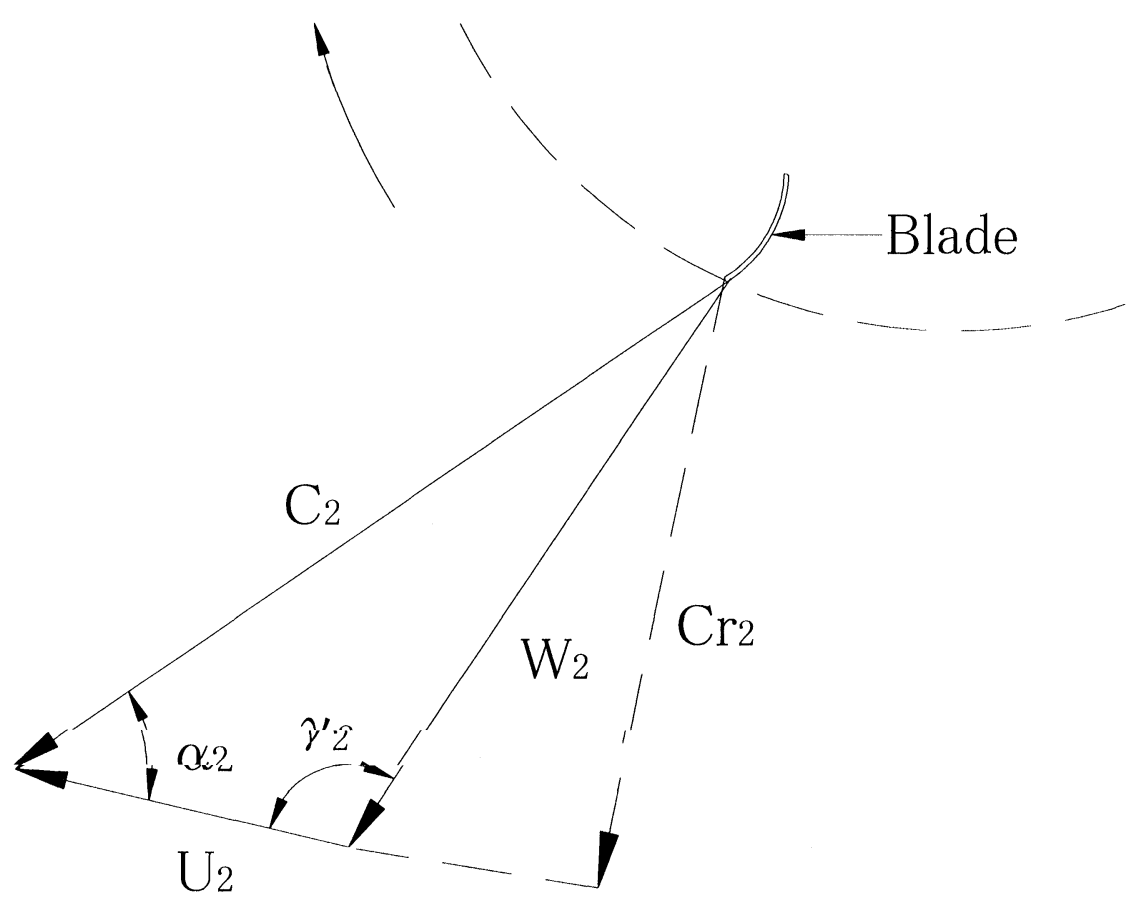

$C_{2}:$ absolute velocity, $W_{2}:$ relative velocity

$U_{2}$ : circumferential velocity of blade tip, $\alpha_{2}:$ absolute outlet angle

$C_{\mathrm{r} 2}$ : radial component of absolute velocity, $\gamma_{2}$ : relative outlet angle

\section{FIGURE 7}

Velocity triangle at outlet of impeller. 
$\prod_{i i 1}^{a}$
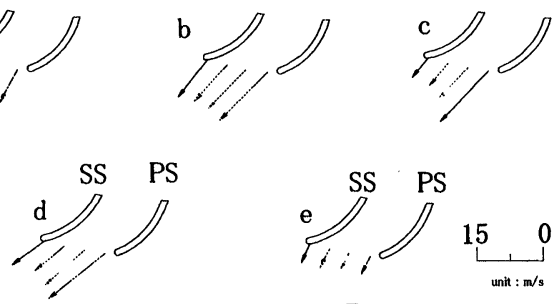

( i ) impeller I
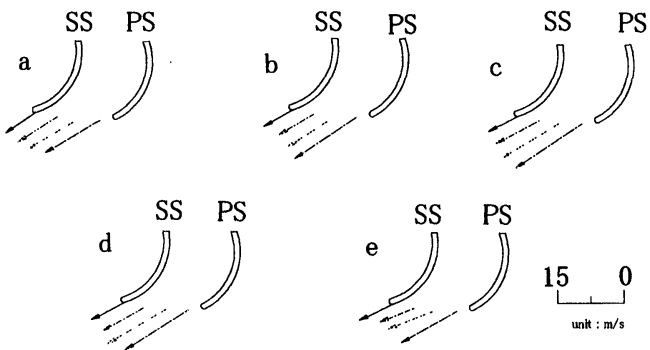

( ii ) impeller II
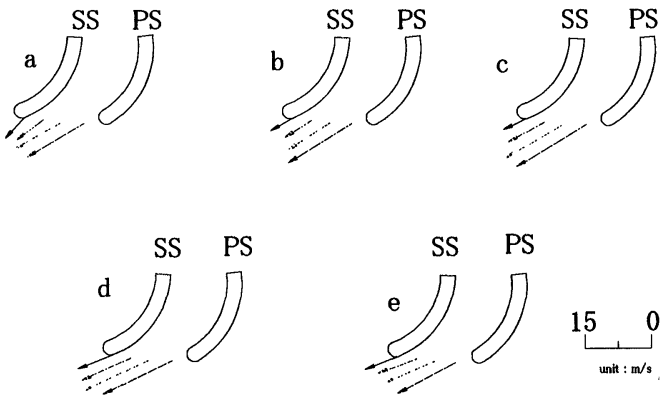

( iii ) impeller VIII
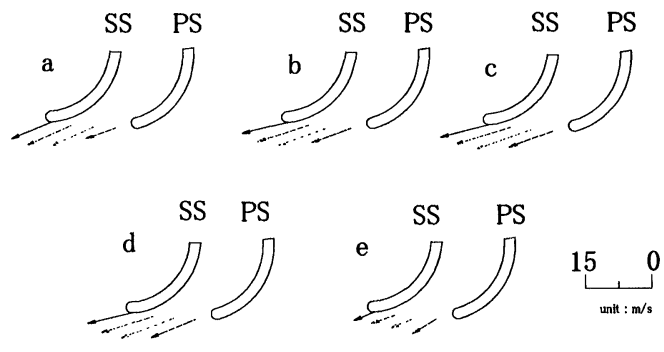

(iv) impeller $\mathbb{X}$

FIGURE 8

Relative velocity distributions at the maximum discharge.

maximum discharge, but it is large at the suction surface of point a, and becomes smaller towards suction surface for impeller VIII. It seems to be arised by the thickness of the blade. According to Yamazaki and Sato (1986), the portion of blade wake in one blade pitch is given by

$$
\sigma=Z t / \pi D_{2} \cos \left(\pi-\beta_{2}\right)
$$
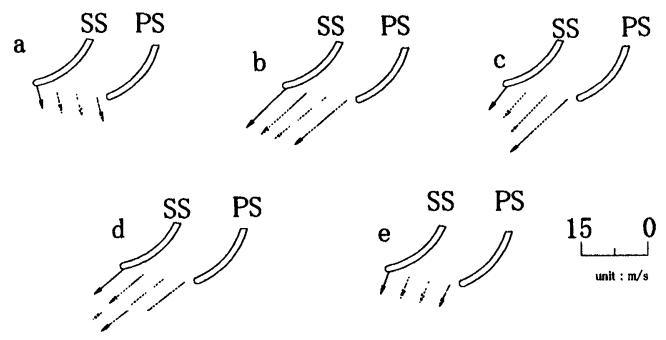

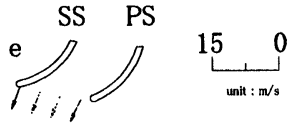

( i ) impeller I
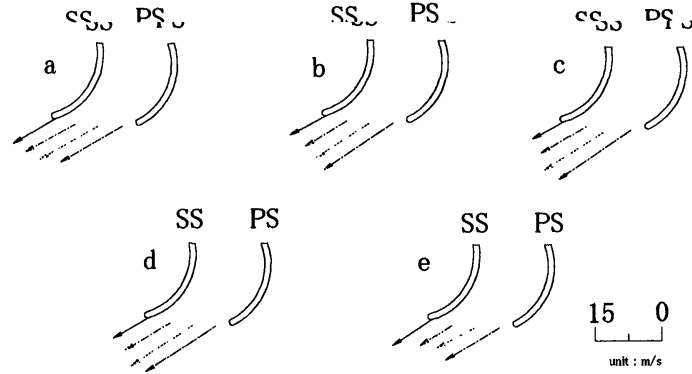

( ii ) impeller II
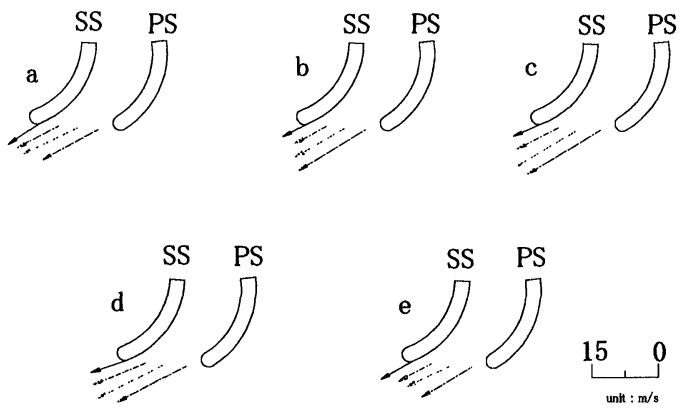

( iii ) impeller VIII
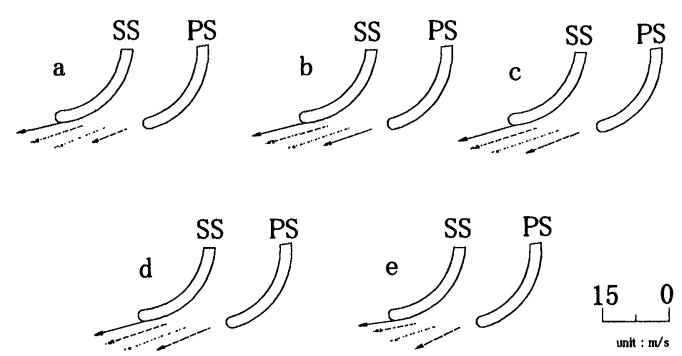

(iv ) impeller IX

FIGURE 9

Relative velocity distributions at the design discharge.

The calculated values, according to this equation, are shown in Table II. From this, it becomes clear that the effect of the wake is larger for impeller VIII. The flow goes along the blade surface on the pressure surface near the hub, but it rotates along the runner just after the outlet of impeller IX, as shown in Figs. 8 and 9 . The outlet angle $160^{\circ}$ of impeller IX seems to be too large. 


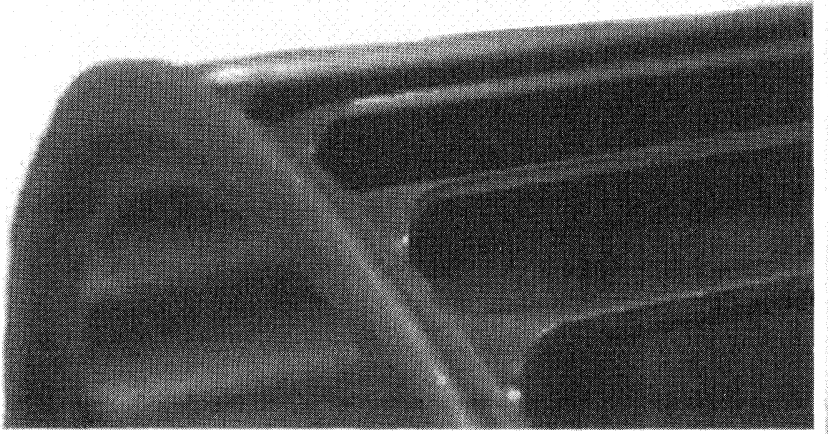

i ) Impeller I

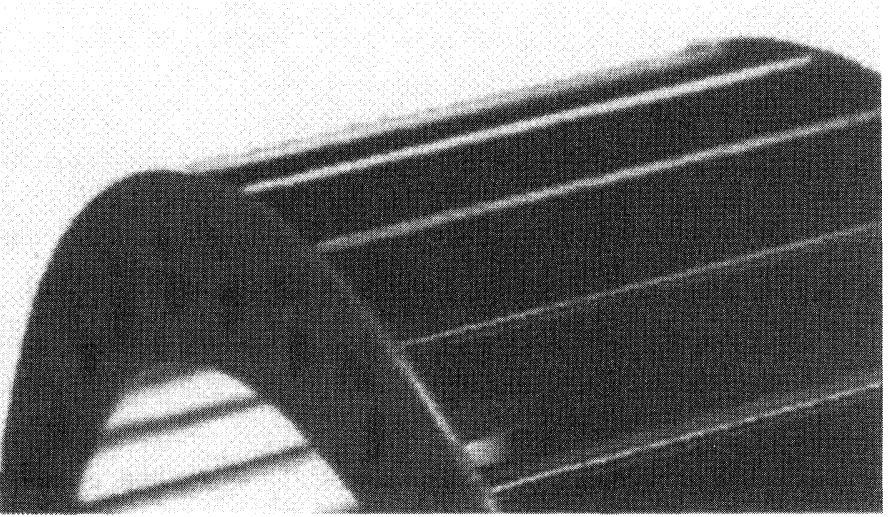

ii ) Impeller II

FIGURE 10

Blade shapes.

\section{Radial Component of Absolute Velocity}

Figures 13 and 14 show the radial component of absolute velocity. The radial component of absolute velocity increases from the suction side to the pressure side at points $\mathrm{c}$ and $\mathrm{d}$, and it is somewhat so at point $b$ for runner I. Then the suction side corresponds to the wake region, and pressure side to the jet region. But at points a and e, a velocity change cannot be seen. The entire blade passage corresponds to the wake region. The cause of this phenomenon is stated above. Velocity increases on the shroud side with an increase in discharge and effective blade passage increases. It can be said that the effective blade passage decreases with a decrease in discharge. The velocity at both ends of the blade becomes smaller at the maximum discharge. But the velocity difference at the center part of the blade passage decreases for the design discharge for impeller II and VIII. The magnitude of the radial component of absolute velocity and its variation is small. The outlet flow rotates with the impeller for this impeller IX.

\section{Flow in the Plane Including the Fan Axis}

Figures 15 and 16 show flow in the plane including the fan axis. The outer frame in these figures corresponds to the flow area of one pitch for every impeller. The left side corresponds to the shroud and the right to the hub side. These figures show that

TABLE II

Relations of blade thickness and wake width

\begin{tabular}{lccccc}
\hline Impeller & $\sigma$ & $Z$ & \multicolumn{1}{c}{$t$} & \multicolumn{1}{c}{$D_{2}$} & $\beta_{2}$ \\
\hline I & 0.0922 & 38 & 1.1 & 159.9 & 154.5 \\
II & 0.0767 & 36 & 1 & 159.3 & 159.6 \\
VIII & 0.1900 & 36 & 2.4 & 160 & 154.8 \\
IX & 0.1537 & 36 & 2.1 & 160.1 & 167.9 \\
\hline
\end{tabular}

flow separates on the shroud side for every impeller blade. This shows that there is a large vortex on the shroud side, as is stated by Yamazaki and Sato (1987). But there are some differences in the magnitude of vortex. The vortex is large for impellers I and IX, and small for impellers II and VIII. It seems that there is some relation to the blade inclination angle. For impellers I and IX, which have a large vortex, there is a large inclination angle. Flow separation also can be seen on the hub side for impeller VIII. The flow goes as if it keeps away this vortex, and it
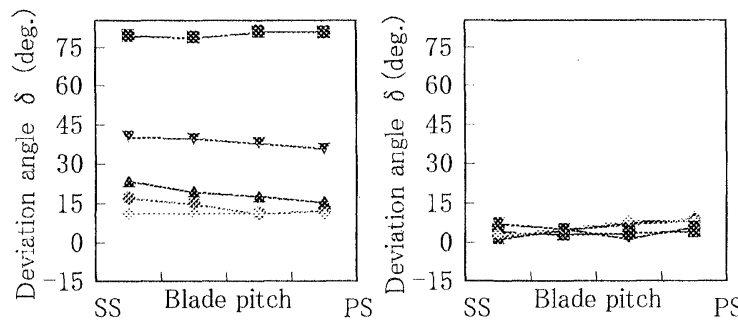

i ) impeller I

ii ) impeller II

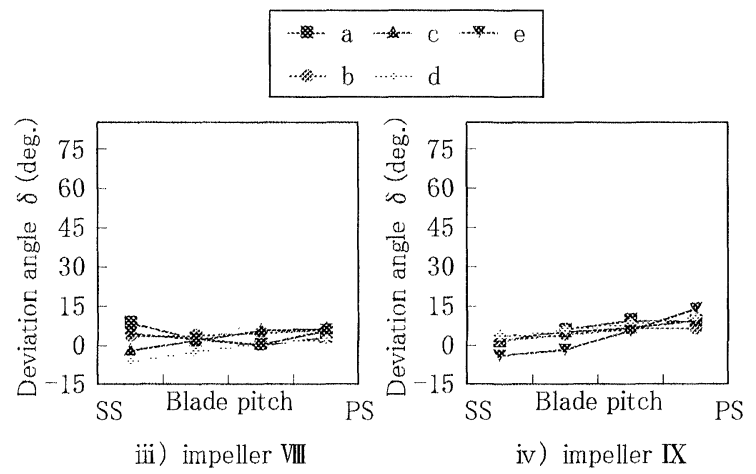

FIGURE 11

Deviation angle at the maximum discharge. 

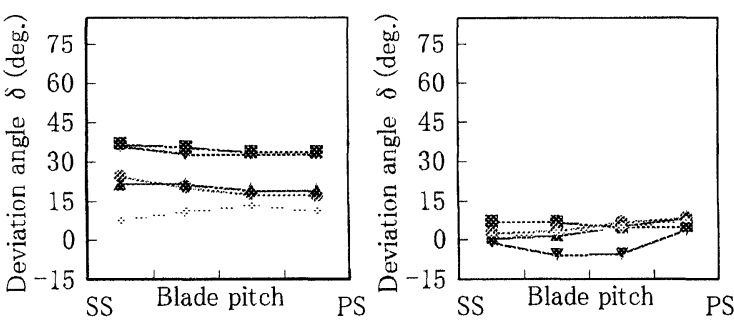

i) impeller I

ii ) impeller II

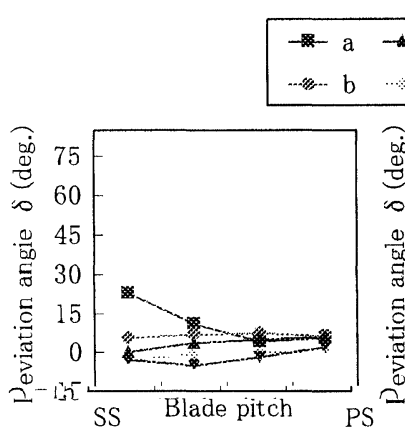

iii) impeller VIII
FIGURE 12

Deviation angle at the design discharge.

concentrates in the center part as it comes near the suction surface. The flow in the impeller shows somewhat different distributions. It seems that the inclination angle and the blade thickness have an influence on the outlet velocity distribution, and a complicated three-dimensional flow arises.

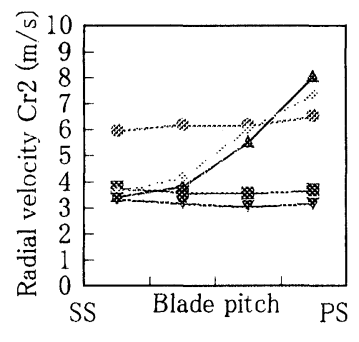

i ) impeller I

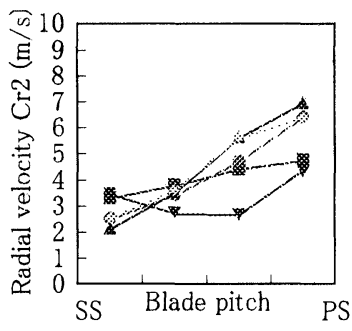

ii ) impeller II

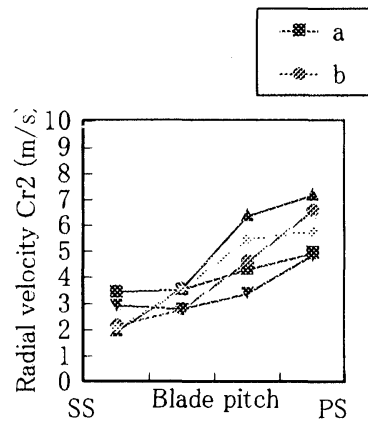

iii) impeller VIII
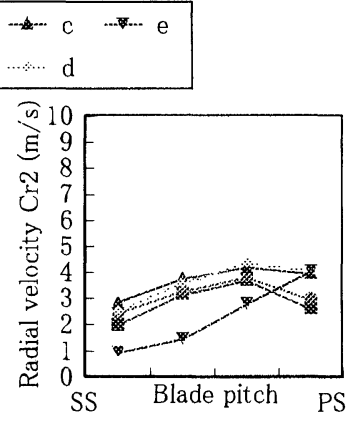

iv) impeller $\mathrm{XX}$
FIGURE 13

Radial component of absolute velocity at the maximum discharge.

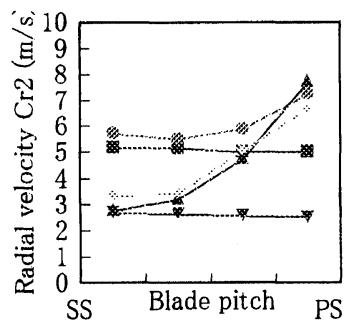

i ) impeller I

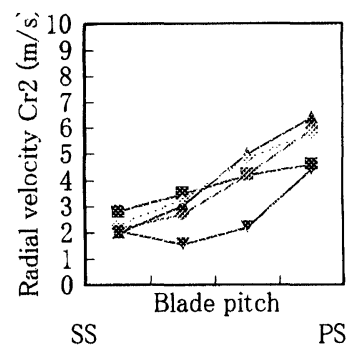

ii ) impeller II

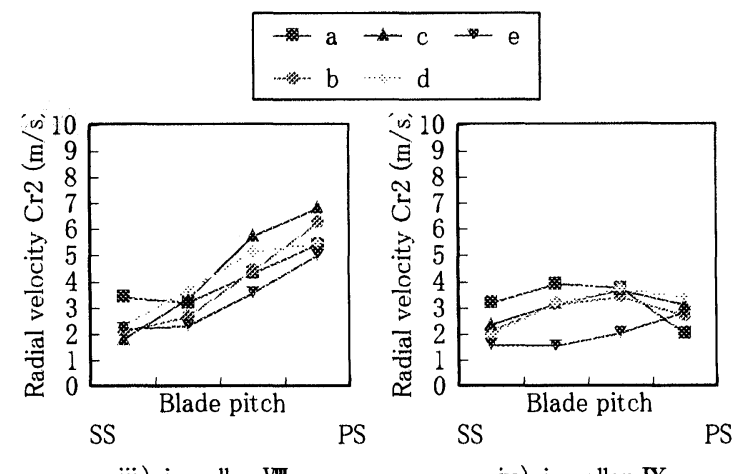

iii) impeller VIII

iv) impeller IX

\section{FIGURE 14}

Radial component of absolute velocity at the design discharge.

\section{THE OPTIMUM DESIGN OF BLADE SHAPE}

Based on the results from performance tests and blade outlet velocity distributions, the optimum design of the blade shape was considered. Considering the experimental results and the three-dimensional inlet flow to the impeller, the most suitable inlet angle will be $75 \sim 90^{\circ}$. According to the measured results of blade outlet flow, the radial component of absolute velocity becomes smaller for the impeller with an outlet angle larger than $160^{\circ}$. Flow seems to attach to the impeller and rotate with
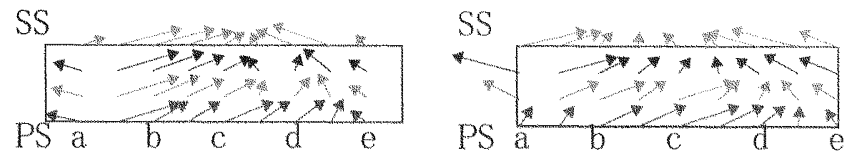

i ) Impeller I

ii ) Impeller II
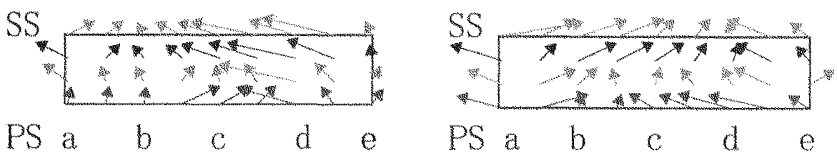

iii) Impeller vill

iv ) Impeller IX

FIGURE 15

Velocity distribution in the $\mathrm{U}-\mathrm{V}$ plane at the maximum discharge. 


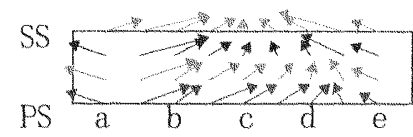

i) Impeller I

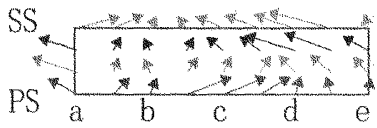

iii) Impeller VIII

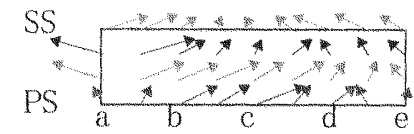

ii ) Impeller $\mathrm{II}$

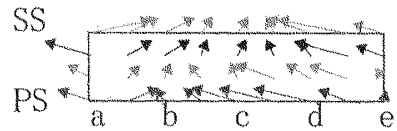

iv) Impeller IX

\section{FIGURE 16}

Velocity distribution in the U-V plane at the design discharge.

the impeller blade after it goes out of the impeller, because the outlet angle is too large. This is the reason for the drop in the discharge. This is because the blade outlet angle is large and the flow rotates with the impeller. The impeller with good performance had an outlet angle of more than $150^{\circ}$. From these facts the most suitable outlet angle will be $150 \sim 160^{\circ}$. For the runner with inlet angle of $75 \sim 90^{\circ}$ and outlet angle of $150 \sim$ $160^{\circ}$, the suitable inclination angle will be $35^{\circ}$ or so. The proper order in deciding the blade shape is considered to be, first, inlet angle; next, the inclination angle; and then blade outlet angle. The following inclination ratio $I_{r}$ was defined in order to decide the most suitable inclination angle for a certain inlet angle:

$$
I_{r}=\left|\theta / \beta_{1}\right|
$$

Variations of the maximum pressure, the maximum efficiency, and the maximum discharge with the inclination angle are shown in Fig. 17. It shows that all items take the maximum value at inclination ratio $I_{r}=0.41$. The fact, that all the values are highlighted at $I_{r}=0.41$, also comes from the thickness of the blade. As $I_{r}=0.41$ is from runner II, its thickness is $1.0 \mathrm{~mm}$. As for impeller VIII with a blade thickness of $2.4 \mathrm{~mm}$, the effect of

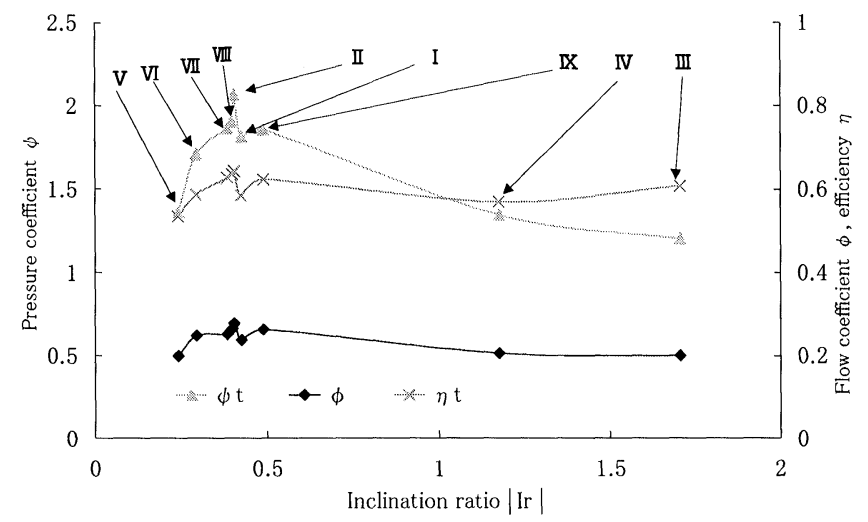

FIGURE 17

Inclination ratio $I_{\mathrm{r}}$ and performance. blade thickness and pressure loss is large. The blade must be as thin as possible. As total pressure coefficient, efficiency, and discharge coefficient take a small value at $I_{r}=0.43$, as it corresponds to runner $I$, as stated above, the flow at points a and e accompany separation. To prevent the collision of flow at the entrance, it seems that it may be better to take a small inlet angle, but it also makes the discharge smaller. On the other hand, if we take an inlet angle $90^{\circ}$, the inlet collision loss will be larger, but as the flow is increasing, the loss will be beneath notice.

\section{CONCLUSIONS}

In this study, performance tests and measurements of velocity distributions at the outlet of the impeller were performed using nine impeller blades with nearly the same inner and outer diameters and width in the same casing. The numbers of blades were $Z=36$, excepting impeller I. For the best condition of the blade shape, the best inclination ratio is 0.41 . The maximum pressure, the maximum efficiency, and the maximum discharge take the maximum value at this inclination ratio. The suitable inlet angle is $\beta_{1}=90^{\circ}$, and that of the outlet angle is $150 \sim 160^{\circ}$. The blade inclination angle influences the magnitude of the vortex at the shroud side.

Other than the inclination ratio, blade thickness is a major factor in improving fan performance. The effect of blade thickness is clear from the measured results of velocity distributions. The best blade thickness is a blade as thin as possible.

\section{NOMENCLATURE}

$D_{1} \quad$ inner diameter of impeller

$D_{2} \quad$ outer diameter of impeller

$l \quad$ blade chord

$b \quad$ blade width

$\beta_{1} \quad$ blade inlet angle

$\beta_{2} \quad$ blade outlet angle

$I_{r} \quad$ inclination ratio

$t \quad$ thickness of blade

$Y \quad$ width of blade passage

$Z \quad$ number of blades

$\Psi \quad$ pressure coefficient

$\Phi$ discharge coefficient

$\eta \quad$ efficiency of fan

$\sigma \quad$ portion of blade wake in a blade pitch

$\delta \quad$ deviation angle $\delta=\beta_{2}-\gamma_{2}$

$\gamma_{2}$

relative outlet angle of blade

\section{Subscripts}

1 inlet of blade

2 outlet of blade

$s \quad$ static pressure

$d \quad$ dynamic pressure

$t$ total pressure

max. the maximum value 


\section{REFERENCES}

Adachi, T., 1995, Turbomachinery, (in Japanese), vol. 23, no. 6, pp. 339-347.

Kadota, S., et al., 1994, Experimental Study on Low-Noise Multiblade Fan (1st Report, Visualization of Three-Dimensional Flow between Blades), Trans. JSME, Ser. B, (in Japanese), vol. 60, no. 570, pp. 102-107.

Kawaguchi, K., et al., 1994, Experimental Study on Noise Reduction of Multiblade Fan (2nd Report, Relation of Flow between Fan Blades and Pressure Fluctuations), Trans. JSME, Ser. B, (in Japanese), vol. 60 , no. 570, pp. 108-113.

Morinushi, K., 1991, Noise Source of a Multiblade Fan, Trans. JSME, Ser. B, (in Japanese), vol. 57, no. 543, pp. 3837-3844.

Nakajima, K., et al., 1986, Turbomachinery, (in Japanese), vol. 14 , no. 10 , pp. 577-584.

Nakajima, K., et al., 1988, Turbomachinery, (in Japanese), vol. 16, no. 12 , pp. $677-683$.

Ogino, K., 1998, Turbomachinery, (in Japanese), vol. 26, no. 9, pp. 539-541.

Raj, D., and Swim, W. B., 1981, Measurements of the Mean Flow
Velocity Fluctuations at the Exit of an FC Centrifugal Fan Rotor, Trans. ASME, J. Engng. for Power, 103-2, pp. 393-399.

Totsuka, J., et al., 1996, Flow Instabilities Observed in Sirocco Fan Impeller, Trans. JSME, Ser. B, (in Japanese), vol. 62, no. 594, pp. 684-691.

Yamamoto, K., et al., 1995, Turbomachinery, (in Japanese), vol. 23, no. 10, pp. 604-609.

Yamazaki, S., and Sato, R., 1986, An Experimental Study on the Aerodynamic Performance of Multi-Blade Blowers (1st Report, Measurement of Flow Patterns within Blowers), Trans. JSME, Ser. B, (in Japanese), vol. 52, no. 484, pp. 3987-3992.

Yamazaki, S., and Sato, R., 1987, An Experimental Study on the Aerodynamic Performance of Multi-Blade Blowers (2nd Report, Prediction of the Shaft Power), Trans. JSME, Ser. B, (in Japanese), vol. 53, no. 485, pp. 108-113.

Yamazaki, S., Sato, R., and Ohkuma, T., 1987, An Experimental Study on the Aerodynamic Performance of Multi-Blade Blowers (3rd Report, Prediction of the Pressure Losses in Blowers), Trans. JSME, Ser. B, (in Japanese), vol. 53, no. 490, pp. 17301735 

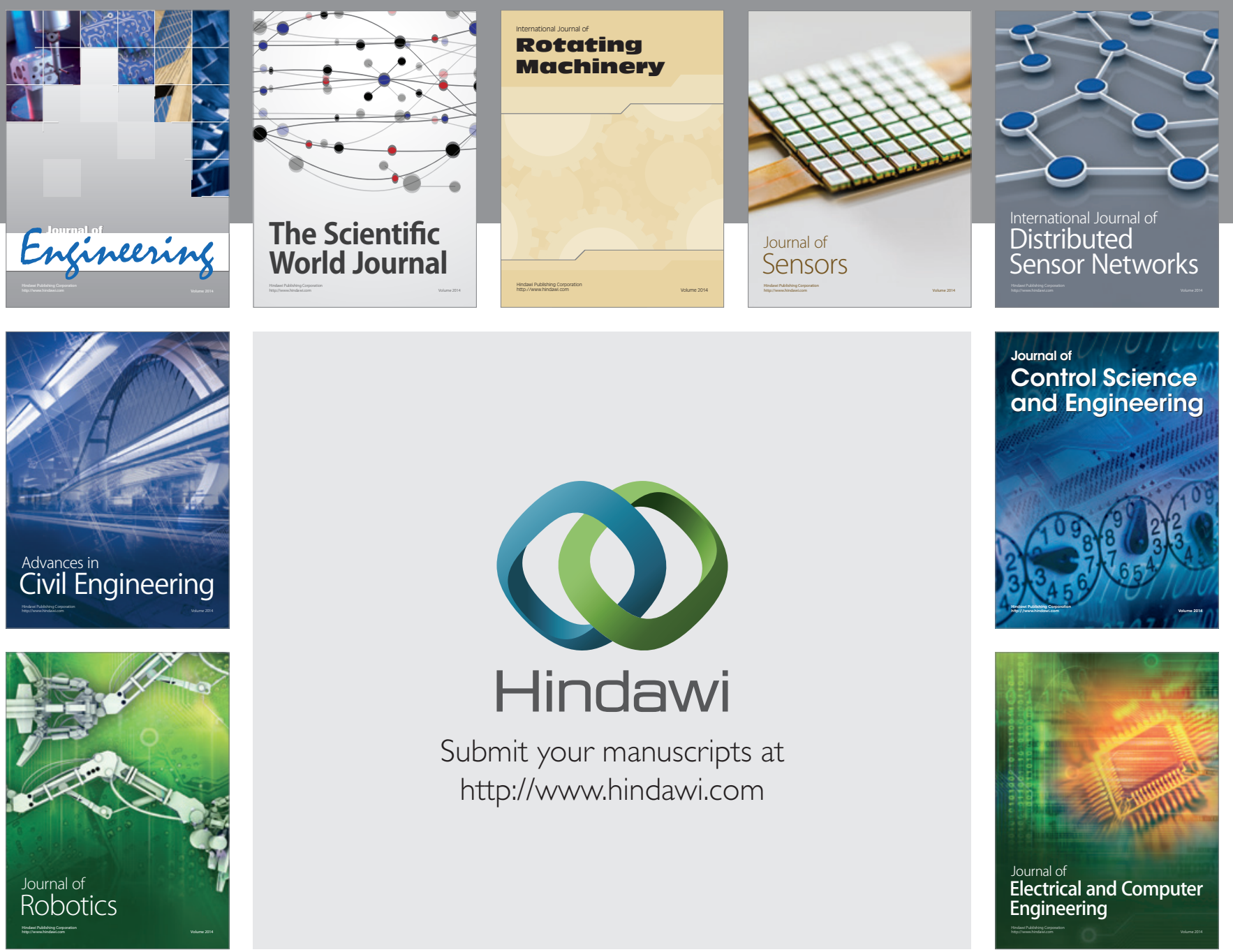

Submit your manuscripts at

http://www.hindawi.com
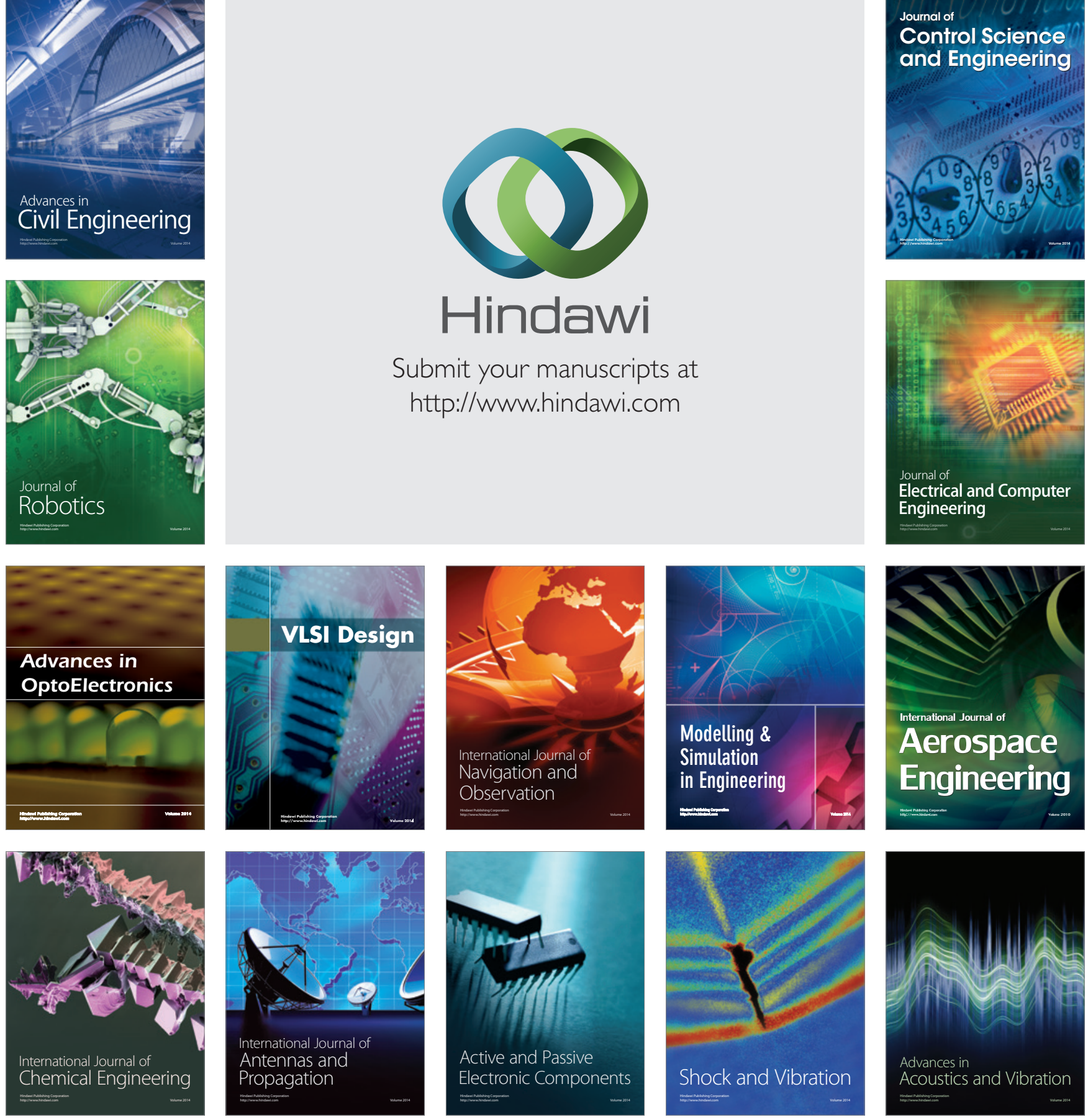